\title{
Pyricularia grisea Isolates Causing Gray Leaf Spot on Perennial Ryegrass (Lolium perenne) in the United States: Relationship to P. grisea Isolates from Other Host Plants
}

\author{
Mark L. Farman
}

Department of Plant Pathology, University of Kentucky, Lexington 40546.

Accepted for publication 29 October 2001.

\begin{abstract}
Farman, M. L. 2002. Pyricularia grisea isolates causing gray leaf spot on perennial ryegrass (Lolium perenne) in the United States: Relationship to P. grisea isolates from other host plants. Phytopathology 92:245-254.

Gray leaf spot of perennial ryegrass (prg) (Lolium perenne), caused by the fungus Pyricularia grisea (teleomorph = Magnaporthe grisea), has rapidly become the most destructive of all turf grass diseases in the United States. Fungal isolates from infected prg were analyzed with several molecular markers to investigate their relationship to $P$. grisea strains found on other hosts. All of the molecular markers used in this study revealed that isolates from prg are very distantly related to those found on crabgrass. Fingerprinting with MGR586 (Pot3) revealed zero to three copies of this transposon in the prg pathogens, distinguishing them from isolates pathogenic to rice, which typically have more than 50 copies of this element. RETRO5, a newly identified retroelement in $P$.

prg. The MAGGY retrotransposon was unevenly distributed in the prg pathogens, with some isolates lacking this element, some possessing six to eight copies, and others having 10 to 30 copies. These results indicated that the $P$. grisea isolates causing gray leaf spot are distinct from those found on crabgrass, rice, or Setaria spp. This conclusion was supported by an unweighted pair-group method with arithmetic average cluster analysis of single-copy restriction fragment length polymorphism haplotypes. Fingerprints obtained with probes from the Pot2 and MGR583 transposons revealed that the prg pathogens are very closely related to isolates from tall fescue, and that they share similarity with isolates from wheat. However, the wheat pathogens had fewer copies of these elements than those found on prg. Therefore, I conclude that P. grisea isolates commonly found on other host plant species did not cause gray leaf spot epidemics on prg. Instead, the disease appears to be caused by a $P$. grisea population that is specific to prg and tall fescue.
\end{abstract} grisea, was present at a copy number of $>50$ in isolates from rice and Setaria spp. but only six to eight copies were found in the isolates from

Incidences of gray leaf spot in perennial ryegrass (prg) have increased dramatically in recent years and epidemics have occurred with alarming regularity. The first report of Pyricularia grisea causing disease on prg was in Pennsylvania in 1992 (19). However, the fungus was identified in a diseased prg fairway on a Maryland golf course as early as 1985 (3). The disease was sporadic until 1995, when the long hot summer experienced across much of the central United States created favorable conditions for disease development and resulted in an epidemic (3). In 1996 and 1997, significant but isolated disease incidences were recorded throughout the central United States, and an epidemic occurred again in 1998, with the disease spreading as far west as Nebraska and north to Rhode Island $(12,28,32)$.

Why has there been such a sudden and devastating emergence of this disease? It is notable that recent epidemics have coincided with extended periods of high heat humidity, conditions that are particularly stressful to cool season turf grasses like prg. In addition, the frequent irrigation of golf course fairways is particularly conducive to infection by $P$. grisea $(17,19)$. Thus, it has been proposed that such conditions may have permitted infection of prg by spores blown up from rice growing in the Southern states (P. Dernoeden, personal communication). The notion that prg might be susceptible to cross-infection by isolates from other host species comes from the work of Trevathan (31), who showed that annual ryegrass (Lolium multiflorum), a close relative of prg, was

Corresponding author: M. L. Farman; E-mail address: farman@uky.edu

Publication no. P-2001-1231-01R

(C) 2002 The American Phytopathological Society
Additional keywords: DNA fingerprinting, rice blast. infected by $P$. grisea isolates from five different plant species in greenhouse inoculation experiments.

The possibility of cross-infection is an important consideration from the perspective of disease scouting and management. Therefore, the objective of the present study was to determine if $P$. grisea strains normally found in association with other host plants could have played a role in the recent gray leaf spot epidemics. In the United States, there are a number of other host for $P$. grisea occurring throughout the central and mid-atlantic regions where prg is widely grown. This fungus is responsible for severe leaf spotting found on a number of weeds including hairy crabgrass (Digitaria sanguinalis) and yellow, green, and giant foxtails (Setaria glauca, S. viridis, and $S$. faberii, respectively). $P$. grisea also causes disease on German foxtail millet ( $S$. italica), which is widely grown as a forage crop. Also examined in this study were $P$. grisea isolates from tall fescue (Festuca arundinacea), because this turf grass is closely related to prg and is commonly used in the rough areas surrounding golf course fairways and greens.

Recently, it was reported that repetitive DNA fingerprinting and internal transcribed spacer (ITS) sequence data defined a close relationship between $P$. grisea isolates from prg and others from wheat (Triticum aestivum) and finger millet (Eleusine coracana) $(36,37)$. Isolates from these hosts were included in the current study to evaluate this proposed relationship further.

Traditional methods to investigate the possibility of cross infection rely on artificial cross inoculation experiments $(31,33)$. However, most of these tests measure disease resulting from a single cycle of infection. The strong environmental influence on disease development in the field means that it is not possible to translate positive results of cross-infection assays to predict if the 
degree of cross infectivity is sufficient to allow development of an epidemic. Conversely, the presence of genotypic diversity within the pathogen and host populations means that failure to obtain cross infection following inoculation of a limited number of host genotypes with a few pathogen isolates cannot rule out the possibility that cross infection actually occurs in nature. The question of cross infection in a field situation is best addressed in a retrospective manner by the use of molecular markers. Accordingly, to address the possibility that cross infection plays a role in gray leaf spot epidemics on prg, I characterized $P$. grisea isolates collected during disease epidemics with a number of molecular markers.

\section{MATERIALS AND METHODS}

Bacterial strains and plasmids. All clones were maintained in Escherichia coli strain DH5 $\alpha$ (Gibco-BRL, Rockville, MD). Repetitive DNA probes were maintained as plasmid clones in the vector pBluescript $\mathrm{KSII}^{+}$. Cosmid probes were from a genomic DNA library of $P$. grisea strain 2539 , cloned in the vector pMLF1 (20).

Fungal strains. A list of the fungal strains used in this study is presented in Table 1. Single spore cultures were obtained from infected plant material as follows. Leaves with visible lesions were placed on water agar in a petri dish. After $18 \mathrm{~h}$, conidia were lifted from the leaf by rubbing the lesions gently with the tip of a sealed Pasteur pipette. The conidia were then spread across the surface of fresh water agar. Eighteen to twenty-four hours later, a single germinated conidium was picked and transferred to oatmeal agar (34). Cultures obtained from other researchers were single spored by collecting a single germinated spore visualized with a dissecting microscope.

Culture of fungal isolates. Routine culture of fungal isolates was performed on oatmeal agar (34). For DNA isolation, test tubes containing $10 \mathrm{ml}$ of complete medium (34) were inoculated with a single agar plug containing mycelium and grown at $25^{\circ} \mathrm{C}$ with shaking for 7 days. The resulting mycelial ball was freezedried, and the DNA was extracted using a scaled-down version of a protocol described by Raeder and Broda (27). Isolates were stored at $-80^{\circ} \mathrm{C}$ as dried-down cultures in paper disks (34).

Southern hybridization analysis. One microgram of DNA from each fungal isolate was digested with restriction enzyme according to the manufacturer's instructions (New England Biolabs, Beverley, MA). Two hundred nanograms of each digest were then loaded into wells in a $0.7 \%$ agarose gel (BioWhittaker Molecular Applications, Rockland, ME). After electrophoresis, gels were washed and blotted according to the protocol outlined by Thornbury and Farman (29). Blots were cross-linked with UV

TABLE 1. Pyricularia grisea strains used in this study

\begin{tabular}{|c|c|c|c|c|c|}
\hline Isolate & Host $^{\mathrm{a}}$ & $\mathrm{Mat}^{\mathrm{b}}$ & Place of isolation & Year & Collector/source \\
\hline Lp96-1 & Perennial ryegrass & $1-2$ & Griffin Gate $\mathrm{GC}$, ${ }^{\mathrm{c}}$ Lexington, $\mathrm{KY}$ & 1996 & P. Vincelli \\
\hline $\mathrm{FH}$ & Perennial ryegrass & $1-2$ & Fountain Head GC, MD & 1997 & P. Dernoeden \\
\hline $\mathrm{HO}$ & Perennial ryegrass & $1-2$ & Hanover GC, Richmond, PA & 1996 & P. Dernoeden \\
\hline $\mathrm{CHRF}$ & Perennial ryegrass & $1-2$ & Cherry Hill Research Farm, MD & 1996 & P. Dernoeden \\
\hline CHW & Perennial ryegrass & $1-2$ & Chartwell GC, Annapolis, MD & 1996 & P. Dernoeden \\
\hline LpKY97-1 & Perennial ryegrass & $1-2$ & Idle Hour GC, Lexington, KY & 1997 & P. Dernoeden \\
\hline GG9 & Perennial ryegrass & $1-2$ & Griffin Gate GC, Lexington, KY & 1997 & M. Farman, P. Vincelli \\
\hline GG11 & Perennial ryegrass & $1-2$ & Griffin Gate GC, Lexington, KY & 1997 & M. Farman, P. Vincelli \\
\hline GG12 & Perennial ryegrass & $1-2$ & Griffin Gate GC, Lexington, KY & 1997 & M. Farman, P. Vincelli \\
\hline GG13 & Perennial ryegrass & $1-2$ & Griffin Gate GC, Lexington, KY & 1997 & M. Farman, P. Vincelli \\
\hline KS320 & Perennial ryegrass & $1-2$ & Manhattan, KS & 1997 & N. Tisserat \\
\hline KS330 & Perennial ryegrass & $1-2$ & Salina, KS & 1997 & N. Tisserat \\
\hline KS331 & Perennial ryegrass & $1-2$ & Salina, KS & 1997 & N. Tisserat \\
\hline LpOH1 & Perennial ryegrass & $1-2$ & $\mathrm{OH}$ & 1997 & J. Rimelspach \\
\hline $\mathrm{LpOH} 3$ & Perennial ryegrass & $1-2$ & $\mathrm{OH}$ & 1997 & J. Rimelspach \\
\hline RGNJ & Perennial ryegrass & $1-2$ & $\mathrm{NJ}$ & 1996 & S. Vaiciunas, B. Clarke \\
\hline WF9722 & Perennial ryegrass & $1-2$ & Bloomington, IL & 1997 & H. Wilkinson \\
\hline WF9723 & Perennial ryegrass & $1-2$ & Bloomington, IL & 1997 & H. Wilkinson \\
\hline WF9724 & Perennial ryegrass & $1-2$ & Bloomington, IL & 1997 & H. Wilkinson \\
\hline LpKY98-1 & Perennial ryegrass & $1-2$ & Spindle Top Farm, Lexington, KY & 1998 & M. Farman \\
\hline LpKY98-2 & Perennial ryegrass & $1-2$ & Griffin Gate GC, Lexington, KY & 1998 & M. Farman \\
\hline LpRIO0-1 & Perennial ryegrass & $1-2$ & RI & 2000 & N. Jackson \\
\hline LpRIO0-2 & Perennial ryegrass & $1-2$ & RI & 2000 & N. Jackson \\
\hline TFGGA & Tall fescue & $1-2$ & GA & 1997 & W. Uddin, L. Burpee \\
\hline TFRGA & Tall fescue & $1-2$ & GA & 1997 & W. Uddin, L. Burpee \\
\hline FaKY97-1 & Tall fescue & $1-2$ & Idle Hour GC, Lexington, KY & 1997 & M. Farman, P. Vincelli \\
\hline FaMS97-1 & Tall fescue & $1-2$ & MS & 1997 & M. Tomaso-Peterson, L. Trevathan \\
\hline DsKY96-1 & Crabgrass & n.d. & UK Arboretum, Lexington, KY & 1996 & P. Vincelli \\
\hline DsKY98-1 & Crabgrass & n.d. & Griffin Gate GC, Lexington, KY & 1998 & M. Farman \\
\hline CG1 & Crabgrass & n.d. & Dantzler Ct., Lexington, KY & 1998 & M. Farman \\
\hline $\mathrm{CG} 2$ & Crabgrass & n.d. & Dantzler Ct., Lexington, KY & 1998 & M. Farman \\
\hline DcDs1 & Crabgrass & n.d. & Dantzler Ct., Lexington, KY & 2000 & M. Farman \\
\hline DcDs2 & Crabgrass & n.d. & Dantzler Ct., Lexington, KY & 2000 & M. Farman \\
\hline DcDs3 & Crabgrass & n.d. & Dantzler Ct., Lexington, KY & 2000 & M. Farman \\
\hline LIZ1 & Crabgrass & n.d. & Elizabeth St., Lexington, KY & 2000 & M. Farman \\
\hline LIZ2 & Crabgrass & n.d. & Elizabeth St., Lexington, KY & 2000 & M. Farman \\
\hline LIZ3 & Crabgrass & n.d. & Elizabeth St., Lexington, KY & 2000 & M. Farman \\
\hline DsRI00-1 & Crabgrass & n.d. & RI & 2000 & N. Jackson \\
\hline DsRI00-2 & Crabgrass & n.d. & RI & 2000 & N. Jackson \\
\hline
\end{tabular}

(continued on next page)

\footnotetext{
${ }^{a}$ Perennial ryegrass $=$ Lolium perenne $;$ tall fescue $=$ Festuca arundinacea $;$ German foxtail millet = Setaria italica $;$ yellow foxtail =S. glauca $;$ green foxtail $=$ S . viridis $;$ giant foxtail $=S$. faberii $;$ crabgrass = Digitaria sanguinalis/ciliaris; finger millet = Eleusine coracana $;$ weeping lovegrass = Eragrostis curvula $;$ and wheat $=$ Triticum aestivum .

${ }^{\mathrm{b}}$ Mating-type; n.d. $=$ not determined.

${ }^{\mathrm{c}} \mathrm{GC}=$ golf course.
} 
light in a Stratalinker (Stratagene, La Jolla, CA) or a Spectrolinker (Spectronics Corp., Lincoln, NE). Prehybridization and hybridization were performed according to a previously published protocol (29).

Hybridization probes. Repetitive DNA probes used in this study are listed in Table 2. Probes were labeled with $\alpha^{32} \mathrm{P}$ dCTP by an oligolabeling kit (Amersham Pharmacia Biotech, Piscataway, NJ). A fragment of the RETRO5 element was cloned as follows. DNA of isolate SiKY97-2 was digested with PstI and electrophoresed in an agarose gel. After ethidium bromide staining, the 3.7-kb repetitive DNA band was excised, purified with a Qiaquick column (Qiagen Inc., Valencia, CA), and cloned into pBluescript II KS+ (Stratagene). Desired clones were identified by hybridizing colony blots with a probe synthesized by labeling the excised 3.7-kb fraction of DNA. Cosmid clones were labeled with ${ }^{32} \mathrm{P}$ dCTP using nick translation (Gibco-BRL). Single fragment restriction fragment length polymorphism (RFLP) probes were gel-purified and ${ }^{32} \mathrm{P}$-labeled with an oligolabeling kit (Amersham Pharmacia Biotech). A list of the clones used is provided in Table 3.

Cluster analysis of single-copy RFLP haplotypes. Isolates were scored for the presence or absence of each restriction fragment. The presence of a given fragment was noted with a 1 , an absence, 0 . Pairwise similarities were calculated with the formula of Nei and Li (24): $S_{\text {xy }}=2 N_{\text {xy }} /\left(N_{x}+N_{y}\right)$, where $N_{x}$ and $N_{y}=$ the number of fragments in each isolate and $N_{\mathrm{xy}}=$ number of fragments shared between two isolates. A distance matrix was then constructed containing pairwise distances $\left(D_{\mathrm{xy}}\right)$, calculated as $D_{\mathrm{xy}}=$ $1-S_{\mathrm{xy}}$. The distances were used to construct a phenogram using the unweighted pair-group method with arithmetic average (UPGMA) program in the RESTSITE software package (23). A bootstrap analysis based on 1,000 iterations was performed using a program written by Levy et al. (21) for implementation in SAS (SAS Institute, Cary, NC).

TABLE 2. List of repetitive probes used in this study ${ }^{a}$

\begin{tabular}{|c|c|c|c|}
\hline $\begin{array}{l}\text { Repetitive } \\
\text { DNA probe }\end{array}$ & Type of repeat & Probe used & Ref. \\
\hline rDNA & Ribosomal DNA & Whole plasmid & (9) \\
\hline MGR586 & IR transposon & Terminal 0.7-kb SalI fragment & (7) \\
\hline Pot2 & IR transposon & Internal 0.9-kb BamHI fragment & (15) \\
\hline MAGGY & $\begin{array}{l}\text { LTR retro- } \\
\text { transposon }\end{array}$ & $\begin{array}{l}\text { Internal } 1.8-\mathrm{kb} N c o \text { I to Pst } \mathrm{I} \\
\text { fragment }\end{array}$ & (8) \\
\hline RETRO5 & LTR retroelement & Internal $3.7-\mathrm{kb}$ PstI fragment & (5) \\
\hline MGR583 & $\begin{array}{l}\text { Non-LTR } \\
\text { retrotransposon }\end{array}$ & $\begin{array}{l}\text { Internal 0.9-kb ApaI-EcoRI } \\
\text { fragment }\end{array}$ & (14) \\
\hline
\end{tabular}

${ }^{a}$ rDNA from Neurospora crassa; IR = inverted repeat; LTR = long terminal repeat.

TABLE 1. (Continued from preceding page)

\begin{tabular}{|c|c|c|c|c|c|}
\hline Isolate & Host $^{\mathrm{a}}$ & Mat $^{\mathrm{b}}$ & Place of isolation & Year & Collector/source \\
\hline Dc88428 & Crabgrass & n.d. & Philippines & 1988 & R. Nelson \\
\hline $82 \mathrm{~T} 11$ & Rice & $1-2$ & TX & 1982 & M. Levy \\
\hline $91 \mathrm{~T} 32$ & Rice & $1-2$ & TX & 1991 & M. Levy \\
\hline 91L5 & Rice & $1-1$ & LA & 1991 & M. Levy \\
\hline $91 \mathrm{~A} 14$ & Rice & $1-2$ & $\mathrm{AR}$ & 1991 & M. Levy \\
\hline $92 \mathrm{~A} 24$ & Rice & $1-2$ & $\mathrm{AR}$ & 1992 & M. Levy \\
\hline $90 \mathrm{~T} 8$ & Rice & $1-1$ & TX & 1990 & M. Levy \\
\hline SiKY97-2 & German foxtail millet & $1-1$ & Caldwell Co., KY & 1997 & P. Bachi \\
\hline SiKY97-3 & German foxtail millet & $1-1$ & Hopkins, KY & 1997 & P. Bachi \\
\hline YF1 & Yellow foxtail & $1-1$ & Arboretum, Lexington, $\mathrm{KY}$ & 1998 & M. Farman \\
\hline YF2 & Yellow foxtail & $1-1$ & Arboretum, Lexington, $\mathrm{KY}$ & 1998 & M. Farman \\
\hline YF3 & Yellow foxtail & $1-1$ & Arboretum, Lexington, $\mathrm{KY}$ & 1998 & M. Farman \\
\hline $\mathrm{GrF} 1$ & Green foxtail & $1-2$ & Spindle Top Farm, Lexington, KY & 1998 & M. Farman \\
\hline GrF2 & Green foxtail & $1-2$ & Spindle Top Farm, Lexington, KY & 1998 & M. Farman \\
\hline $\mathrm{McC} 1$ & Green foxtail & $1-2$ & McConnell Springs, Lexington, KY & 1998 & M. Farman \\
\hline $\mathrm{McC} 2$ & Green foxtail & $1-2$ & McConnell Springs, Lexington, KY & 1998 & M. Farman \\
\hline Arc1 & Green foxtail & $1-2$ & Arcadia Park, Lexington, KY & 1998 & M. Farman \\
\hline Arc2 & Green foxtail & $1-2$ & Arcadia Park, Lexington, KY & 1998 & M. Farman \\
\hline SvRI00-1 & Green foxtail & n.d. & RI & 2000 & N. Jackson \\
\hline SvRI00-2 & Green foxtail & n.d. & RI & 2000 & N. Jackson \\
\hline GF1 & Giant foxtail & $1-1$ & KY-American, Lexington, KY & 1998 & N. Jackson \\
\hline GF2 & Giant foxtail & $1-1$ & KY-American, Lexington, KY & 1998 & N. Jackson \\
\hline GF00-1 & Giant foxtail & $1-2$ & Southland Park, Lexington, KY & 2000 & M. Farman \\
\hline GF00-2 & Giant foxtail & $1-1$ & Southland Park, Lexington, KY & 2000 & M. Farman \\
\hline GF00-3 & Giant foxtail & $1-1$ & Southland Park, Lexington, KY & 2000 & M. Farman \\
\hline GF00-4 & Giant foxtail & $1-1$ & Southland Park, Lexington, KY & 2000 & M. Farman \\
\hline GF00-5 & Giant foxtail & $1-1$ & Elizabeth Street Park, Lexington, KY & 2000 & M. Farman \\
\hline GF00-6 & Giant foxtail & $1-1$ & Elizabeth Street Park, Lexington, KY & 2000 & M. Farman \\
\hline $\mathrm{Br} 81$ & Wheat & $1-1$ & Brazil & 1991 & D. Tharreau \\
\hline
\end{tabular}




\section{RESULTS}

Comparison of $\boldsymbol{P}$. grisea isolates from prg with isolates from other hosts occurring in the United States. When DNA samples of the P. grisea isolates from prg, rice, crabgrass, and Setaria spp. were digested with PstI and electrophoresed in $0.7 \%$ agarose gels, visualization of the ethidium bromide-stained gel revealed distinctive repetitive DNA banding patterns that were polymorphic among isolates from different hosts (Fig. 1). Southern hybridization analysis showed that the brightest band was due to a conserved PstI site in the ribosomal DNA repeat array (data not shown). In the prg, rice, and Setaria pathogens, the major rDNA band was $\approx 8.5 \mathrm{~kb}$, whereas in the crabgrass pathogens it was $\approx 7.2 \mathrm{~kb}$ (Fig. 1). In addition to the ribosomal repeat, the rice and Setaria pathogens yielded two other repetitive DNA bands that were not visible in the other lanes. The larger band of $5.3 \mathrm{~kb}$ is mostly composed of multiple copies of an internal fragment from the MAGGY retrotransposon, whereas a $3.7-\mathrm{kb}$ band is derived from the RETRO5 retroelement. Neither band was visible in DNA from the prg or crabgrass pathogens. BamHI digestion did not result in obvious repetitive bands in any of the DNA samples.

To determine if gray leaf spot is caused by rice pathogenic strains of $P$. grisea, isolates were fingerprinted with the rice strainspecific transposon, MGR586. Shown on the left in Figure 2 are rice-infecting $P$. grisea isolates representing four of the eight genetic lineages found in the United States. These have the high-

TABLE 3. Plasmid and cosmid clones used as restriction fragment length polymorphism (RFLP) probes ${ }^{\mathrm{a}}$

\begin{tabular}{lclc}
\hline Probe & Chromosome & Features & Ref. \\
\hline AVR1-CO39 & 1 & Avirulence gene & $(6)$ \\
MAT1-2 & 7 & Mating-type gene & $(16)$ \\
cos18O3 & 1 & Contains AVR1-CO39 gene & $(6)$ \\
A22-7-E & 2 & BUF1 gene & $(4)$ \\
A13-2-H & 2 & BUF1 gene & $(4)$ \\
11-11-N & 2 & Linked to BUF1 gene & $(4)$ \\
16-1-B & 2 & RFLP-marker & $(25)$ \\
$55-4-C$ & 3 & RFLP marker & $(25)$ \\
24-8-C & 3 & Peptide synthetase gene & Unpublished \\
19-10-A & 5 & TRP1 gene & Unpublished \\
28-7-F & 7 & GPD1 gene & Unpublished \\
$5-12-A$ & nd & RAD51 homolog & Unpublished \\
\hline
\end{tabular}

a Unpublished indicates unpublished data by M. L. Farman; nd = not determined. copy MGR586 fingerprint patterns typical of rice pathogenic isolates $(11,22,23)$. Also shown are 10 representative isolates from prg. Fifteen of eighteen prg isolates analyzed had three copies of MGR586, two had two copies (lanes 14 and 15), and one isolate, CHW, lacked this element altogether (lane 18). Not shown in Figure 2 are four isolates from tall fescue, each of which had three copies of MGR586 and yielded fingerprint profiles that were identical to the gray leaf spot profile seen in most lanes in Figure 2 containing prg pathogen DNA. In addition, several very weakly hybridizing fragments were observed in DNA of the isolates from prg and tall fescue, indicating that they contain multiple copies of a divergent element related to MGR586. The MGR586 probe hybridized very weakly or not at all to DNA of $P$. grisea isolates from the other host species (data not shown).

In Figure 1, the intensely staining band at a molecular size of $5.3 \mathrm{~kb}$ was clearly visible only in the lanes containing DNA from the Setaria pathogens. From previous studies, this band was known to correspond to the MAGGY retrotransposon $(8,30)$. Consequently, MAGGY was expected to be a useful probe for distinguishing the prg pathogens from isolates found on Setaria spp. As expected, the MAGGY probe hybridized intensely to the $5.3-\mathrm{kb}$ band visible in the ethidium bromide-stained gel (data not shown). However, hybridization also occurred to $5.3-\mathrm{kb}$ fragments in DNA from some of the prg pathogens, although the signals were much less intense (data not shown). To estimate the number of MAGGY copies in each isolate, the probe was hybridized with blots of BamHI-digested DNA, which normally yields one hybridizing fragment per element copy. This revealed that the rice and Setaria pathogens had $>50$ copies of MAGGY in their genomes (Fig. 3). The MAGGY fingerprints of the prg pathogens revealed three groups. Group 1 was represented by two isolates that had no copies of MAGGY in their genomes, group 2 contained 13 isolates that exhibited one major hybridization signal and between five and seven weaker ones (visible on overexposure of the image in Figure 3), and the third group was represented by seven isolates possessing $\approx 10$ to 30 MAGGY copies. Ten isolates from prg are shown in Figure 3: two from group 1, five from group 2, and three from group 5. The estimated copy numbers of MAGGY in isolates FH, LpOH1, and KS330 (Fig. 2, lanes 13 to 15) were 20, 15, and 28 , respectively (bands of greater intensity were counted as two copies). Isolates from crabgrass showed very weak hybridization to a single fragment upon overexposure of the phosphorimage (data not shown).

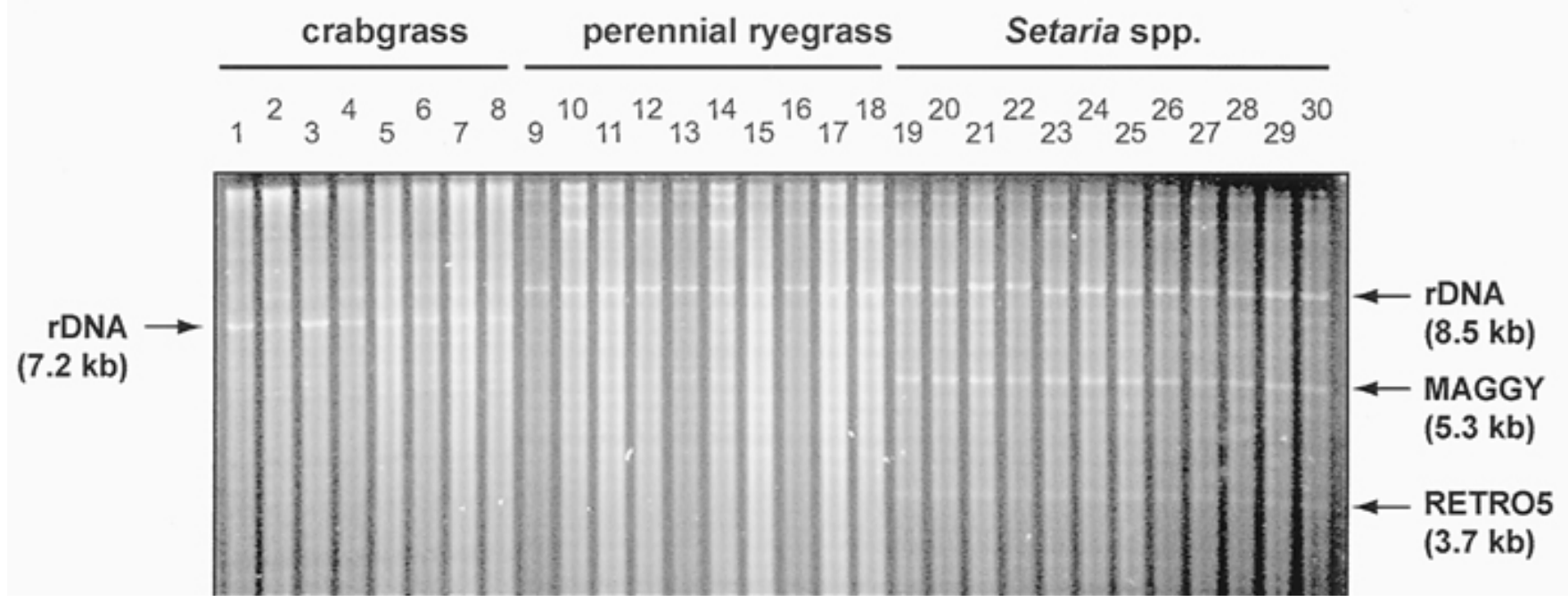

Fig. 1. Polymorphisms in repetitive DNA banding patterns. DNA samples were digested with PstI, electrophoresed through a $0.7 \%$ agarose gel (approximately $200 \mathrm{ng}$ per lane). The gel was stained with ethidium bromide and imaged. Isolates are as follows: lane 1, DsKY98-1; 2, DsKY98-2; 3, DcDs1; 4, DcDs2; 5, DcDs3; 6, LIZ1; 7, LIZ2; 8, LIZ3; 9, HO; 10, Lp96-1; 11, FH; 12, LpOH1; 13, KS330; 14, KS320; 15, GG11; 16, GG9; 17, CHRF; 18, CHW; 19, ARC1; 20, McC1; 21, YF1; 22, YF2; 23, GrF1; 24, GrF2; 25, GrF3; 26, GrF5; 27, GrF6; 28, GrF4; 29, GF1; and 30, GF2. The identities and sizes of specific repetitive DNA bands are indicated. Hosts of origin are noted above respective lanes. 
The 3.7-kb repetitive DNA band that was visible in DNA from the rice and Setaria pathogens after ethidium bromide staining of the gel appeared to be lacking in the DNA from the prg pathogens. The DNA species corresponding to this repetitive fragment was cloned and used to probe PstI-digested DNAs of all isolates. As expected, an intense hybridization signal was observed at the predicted location $(3.7 \mathrm{~kb})$ in all the lanes containing DNA from the Setaria pathogens (Fig. 4). There were also many additional signals, indicating that several copies of the element were polymorphic for the internal Pst I sites. The probe also hybridized intensely to DNA from the rice pathogens (data not shown). In contrast, the DNA samples from the prg and crabgrass pathogens exhibited only a few, weak signals with this probe (Fig. 4). Nucleotide sequence analysis revealed that the probe was an internal fragment of a recently identified retrotransposon (5) related to elements found in rice (26), tobacco (10), and Arabidopsis spp. (13). This element is named RETRO5 because it is the fifth retroelement reported in P. grisea.

Two other repetitive probes that were used in this study were derived from the Pot2 (15) and MGR583 transposons (14). Pot2 fingerprinting revealed that the isolates from prg had considerably fewer copies of Pot 2 than the isolates found on crabgrass, rice, and Setaria spp. (data not shown), supporting the conclusions drawn from the results obtained with the MGR586 and RETRO5 probes. In contrast, the MGR583 probe was generally not useful for determining relationships among isolates because they all had a similar copy number. In addition, the MGR583 fingerprint patterns did not correlate with host of origin, because in the crabgrass, rice, and Setaria pathogen populations, there was significant diversity even between isolates from the same host (data not shown). All of the repetitive probes used in this study, including Pot2 and MGR583, resulted in very similar fingerprint patterns within the prg pathogen population. The isolates from tall fescue also shared these patterns (data not shown), indicating that these closely related grasses are infected by a single pathogen population that has limited genetic diversity.

Relationship to $P$. grisea isolates from finger millet (E. coracana) and wheat (T. aestivum). Viji et al. $(36,37)$ recently reported that the ITS region of the rDNA repeat in a gray leaf spot isolate was identical to sequences found in P. grisea isolates from finger millet (E. coracana) and wheat ( $T$. aestivum). To explore this relationship further, Pot2 and MGR583 fingerprinting, as well as single-copy RFLP (scRFLP) analysis, were used to determine if the genetic similarity extended to other chromosomal loci.

Fingerprints obtained with both Pot2 and MGR583 revealed that isolates from finger millet are not closely related to those causing gray leaf spot (data not shown). In contrast, the Pot2 fingerprints of three representative wheat pathogens shared a number of hybridizing bands with the prg isolates (Fig. 5). Despite this similarity, however, most of the strains from prg had several additional copies of Pot2 (Fig. 5, highlighted with black dots). A notable exception was isolate CHW (Fig. 5, lane 6), whose Pot2 fingerprint pattern showed $\approx 80 \%$ identity to that of isolate $\mathrm{Br} 80$ from wheat (Fig. 5, lane 8). Similar results were obtained with the MGR583 probe-on average the prg pathogens had at least 10 more copies of MGR583 than the wheat pathogens (data not shown). Again, CHW had fewer copies of this element than the other prg isolates and shared $\approx 80 \%$ identity in MGR583 fingerprint with Br80. Similar results were obtained when the Pot 2 and MGR583 probes were used to analyze 24 additional wheat-infecting isolates (data not shown).

$P$. grisea isolates found on prg are resolvable from other host-specific forms by scRFLP analysis. By using various repetitive DNA probes, including rDNA, MGR586, MAGGY, and RETRO5, it was possible to distinguish between the isolates from prg and most of the other host-specific forms of P. grisea. However, as indicated by the MAGGY data, it is possible for isolates from a single host to have a wide variation in the copy number of

some repetitive elements. This means that host species boundaries cannot always be predicted based on the presence or absence of a particular element. For this reason, analysis of scRFLPs was performed to validate the conclusions drawn from the repetitive DNA fingerprinting studies. Nine of eleven probes used were cosmid clones with large (35 to $40 \mathrm{~kb}$ ) inserts, enabling multiple RFLPs to be surveyed at each locus examined. These probes were selected so that RFLPs were monitored on at least five of the seven $P$. grisea chromosomes (Table 3 ).

The scRFLP analysis revealed that the crabgrass pathogens are very distantly related to all of the other $P$. grisea isolates used in this study, including those from prg. Seven probes hybridized to 41 fragments in genomic DNA of the crabgrass isolates, of which at least 34 were completely polymorphic, i.e., similarly sized fragments were not present in any of the other isolates examined (data not shown).

There was much less genetic variation among the other hostspecific forms of the fungus, with only four of the nine cosmid probes identifying polymorphisms. Nevertheless, of the 76 scoreable fragments that hybridized to these four probes, 75 were polymorphic (56 of 60 , if the highly polymorphic crabgrass isolates are excluded). Genetic similarity between each pair of isolates was determined based on the number of shared fragments (24). These similarities were converted to distance values that were

rice

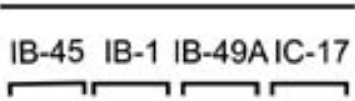

$\begin{array}{llllllll}1 & 2 & 3 & 4 & 5 & 6 & 7 & 8\end{array}$ perennial ryegrass

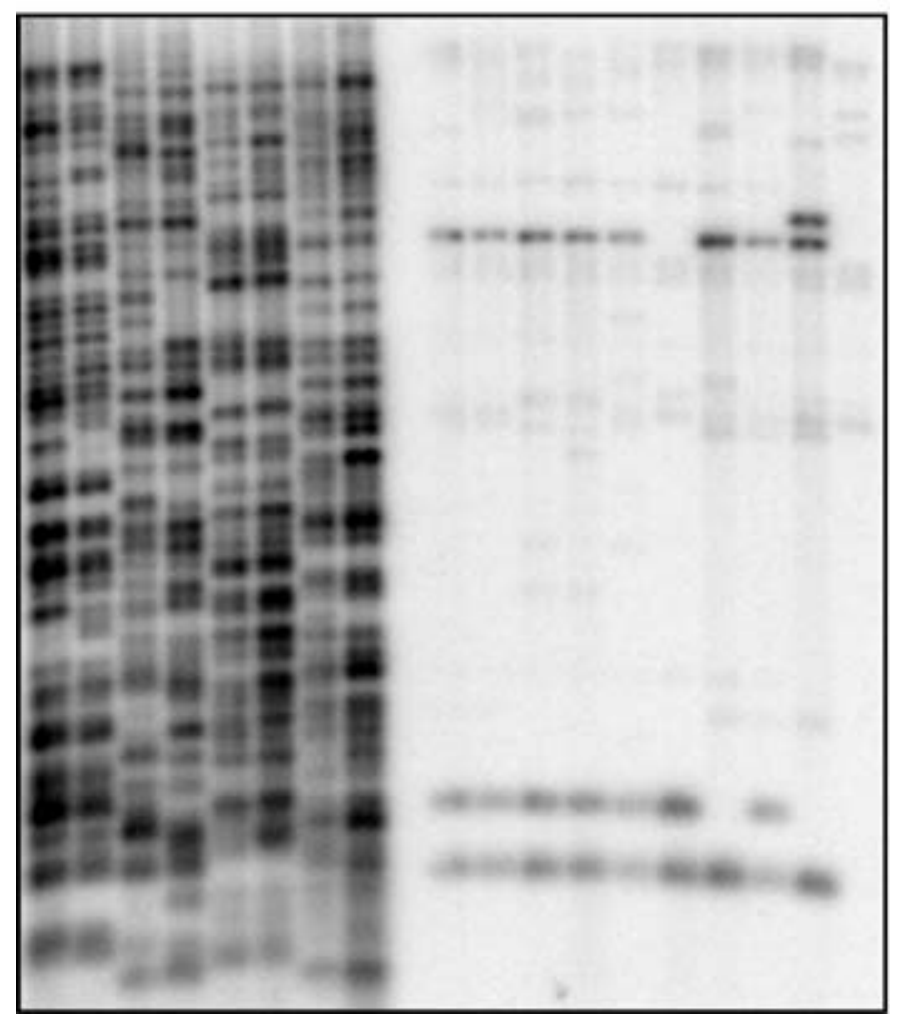

Fig. 2. MGR586 fingerprints of Pyricularia grisea isolates from rice and perennial ryegrass. EcoRI-digested DNAs were electrophoresed in a $0.7 \%$ agarose gel ( $\approx 200 \mathrm{ng}$ DNA per lane). The gel was blotted to a nylon membrane, which was probed with MGR586. The phosphorimage is shown. Isolates are as follows: lane 1, 82T11; 2, 91T32; 3, 89L36; 4, 91L5; 5, 91A4; 6, 92A24; 7, 90T8; 8, 91T14; 9, HO; 10, Lp96-1; 11, FH; 12, LpOH1; 13, KS330; 14, KS320; 15, GG11; 16, GG9; 17, CHRF; and 18, CHW. Hosts of origin are noted above the respective lanes. Race designations of the rice isolates are also shown. 
then analyzed by UPGMA and the results displayed as a phenogram (Fig. 6). Isolates from the same host generally grouped together. Bootstrapping of the distance values at nodes separating each group provided statistical support for nine distinct clusters, whose constituent isolates showed no more than $90 \%$ similarity to members of other clusters at the $95 \%$ confidence level (Fig. 6). These were the crabgrass cluster, a finger millet cluster, the finger millet/goosegrass/weeping lovegrass cluster, the prg/tall fescue/ wheat cluster, three clusters of rice pathogens, and two Setaria pathogen clusters. Isolates within the prg/tall fescue/wheat cluster could not be differentiated from one another with a any degree of statistical confidence. However, these isolates showed less than $60 \%$ similarity to any isolates within the neighboring cluster, which provides strong evidence that they are genetically different from isolates found on other hosts. As a result, the variation at single-copy DNA loci not only supports the conslusions of the fingerprinting study but also reveals that the isolates from $\mathrm{prg} / \mathrm{tall}$ fescue/wheat are quite distantly related to the others. However, it was not possible to infer their closest relatives because the over- lapping confidence intervals at subsequent nodes precluded determination of the branching order.

\section{DISCUSSION}

Gray leaf spot of prg is a relatively new disease and, before this study was initiated, little was known about the $P$. grisea population responsible for the devastating losses of prg turf. The observation that epidemics coincide with extended periods of high heat and humidity indicates that physiological stress of prg is a contributory factor. One possibility is that these conditions may have resulted in a loss of baseline resistance to $P$. grisea. This, with cultural practices that are favorable to the pathogen's infection process, may have led to infection by strains that are normally restricted to other host plant species. To test this hypothesis, molecular markers were used to determine the genetic relationships between isolates causing gray leaf spot on prg and others found on different hosts. If gray leaf spot were due to infection by P. grisea strains normally found on other host plants, this would

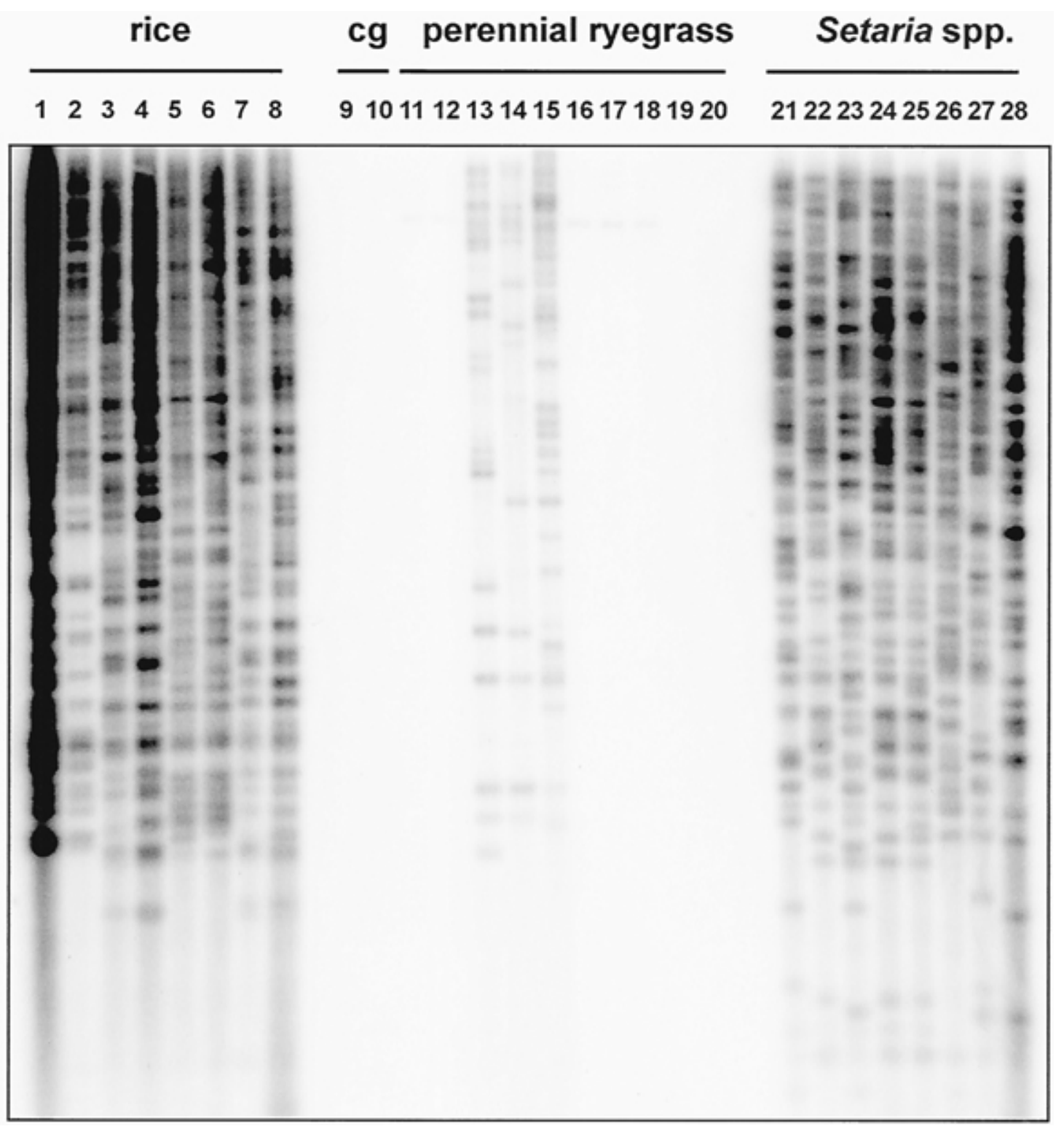

Fig. 3. MAGGY fingerprints of isolates from rice, crabgrass, perennial ryegrass, and Setaria spp. BamHI-digested genomic DNAs of representative isolates were electrophoresed in a $0.7 \%$ agarose gel $(\approx 200 \mathrm{ng}$ DNA per lane) and blotted. The blot was hybridized with the MAGGY probe. The phosphorimage is shown. Isolates are as follows: lane 1, 82T11; 2, 91T32; 3, 89L36; 4, 91L5; 5, 91A4; 6, 92A24; 7, 90T8; 8, 91T14; 9, DsKY98-1; 10, DcDs2; 11, HO; 12, Lp96-1. 13, FH; 14, LpOH1; 15, KS330; 16, KS320; 17, GG11; 18, GG9; 19, CHRF; 20, CHW; 21, Arc1; 22, McC1; 23, YF1; 24, GrF1; 25, GrF3; 26, GrF5; 27, GF1; and 28, SiKY97-1. Hosts of origin are noted above the respective lanes. 
have been reflected in high fingerprint diversity among isolates from diseased prg turf. In addition, this scenario would be expected to result in the detection of fingerprint similarity between isolates from prg and one or more other host species.

All of the molecular markers used in this study provided evidence that $P$. grisea isolates from crabgrass do not cause gray leaf spot. Specifically, they possessed strikingly different rDNA and scRFLP haplotypes, they lacked the MAGGY retrotransposon, and they exhibited a polymorphism for an internal PstI fragment within Pot2 (data not shown). The abundance of scRFLPs in DNA from the crabgrass pathogens, and the observation that all the probes had weaker hybridization signals, likely reflects a significant amount of sequence divergence.

The gray leaf spot isolates were clearly distinguished from the rice pathogens based on the number of fragments hybridizing to MGR586 (Fig. 1). Only four of the at least eight known rice blast lineages found in the United States were included in this study. However, previous studies of much larger numbers of rice-pathogenic isolates of $P$. grisea have shown that the vast majority has multi-copy MGR586 fingerprint patterns similar to those shown in Figure $1(22,35,38)$. Therefore, it is clear that blasted rice did not constitute a source of inoculum for the gray leaf spot epidemics.

The MAGGY probe provided an indication that $P$. grisea strains from Setaria spp. do not play a role in gray leaf spot. All isolates from Setaria spp. analyzed to date have high copy numbers of this element $(8,30)$, whereas most of the prg pathogens had only a few MAGGY copies in their genomes (Fig. 3) (M. Farman, unpublished data). Thus, it is unlikely that these isolates came from diseased Setaria spp. This conclusion was overwhelmingly supported by the results obtained with the RETRO5 probe, which revealed a clear and diagnostic difference in copy number between the prg and Setaria pathogens (Fig. 4).

The copy numbers of MGR586 and RETRO5 probes were not useful for comparing the gray leaf spot pathogens with other hostspecific forms of $P$. grisea including pathogens of finger millet, goosegrass, weeping lovegrass, and St. Augustine grass. This is because these elements are either absent in these other forms or present at a low copy number (data not shown). Surprisingly, even probes derived from the Pot2 and MGR583 transposon, which are both ubiquitous in $P$. grisea $(14,15)$, were not particularly useful for differentiating isolates from different hosts. This is because the resulting fingerprints often showed as much variation within a host group as there was between groups, so that even isolates from the same host often had very different Pot2 and MGR583 fingerprints (data not shown). Based on observations made during this study, single-copy probes are the most useful for making initial comparisons of $P$. grisea isolates from different hosts. Although the majority of the scRFLP loci were monomorphic between the non-crabgrass isolates, the remaining probes identified polymorphisms between (and sometimes within) each of the host-specific forms (data not shown). These latter loci are clearly highly variable between different $P$. grisea populations and, therefore, will likely be useful for analyzing new and poorly characterized $P$. grisea isolates from other host plant species.

The results of this study provide compelling evidence against "opportunistic" infection of prg by $P$. grisea isolates that are normally found on other host species growing in the United States. Instead, the remarkable similarity in fingerprint/RFLP profiles found among members of the prg and tall fescue pathogen populations is consistent with the hypothesis that gray leaf spot is caused by a specific $P$. grisea population that constitutes a hostspecific form of the fungus. The close relationship between isolates from these two hosts is not surprising given that prg and tall fescue are considered to be con-generic (2). Indeed, inoculation studies have shown that $P$. grisea isolates from prg and tall fescue are infectious to both host species (T. Phillips and M. Farman, unpublished data). Interestingly, however, Pot2 and MGR583 fingerprinting revealed that the U.S. gray leaf spot isolates were quite unlike $P$. grisea isolates found on prg in Japan (M. Farman, unpublished data).

The relationship between gray leaf spot and wheat blast is not so clear. Viji et al. reported that the ITS sequence of rDNA in the prg pathogens was identical to those found in P. grisea isolates from wheat and Eleusine spp. (36,37). In addition, Urashima et al. (33) reported that many of the wheat isolates used in this study readily infect prg in inoculation assays. These data suggested that gray leaf spot could be caused by $P$. grisea isolates that are normally found on wheat. However, the results reported in this manuscript, along with other lines of evidence, indicate that this is probably not the case. The present study showed that while these

\section{$\begin{array}{lll}\text { crabgrass } & \text { Setaria spp. } & \text { perennial ryegrass }\end{array}$}

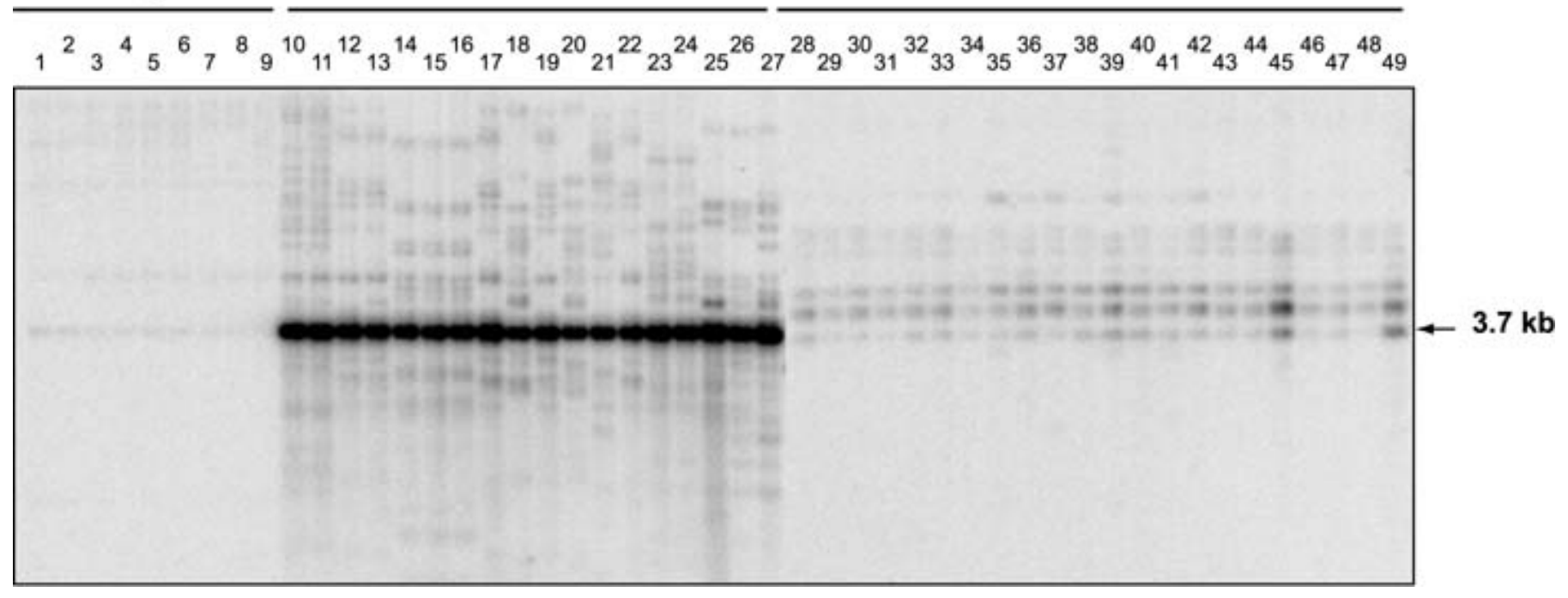

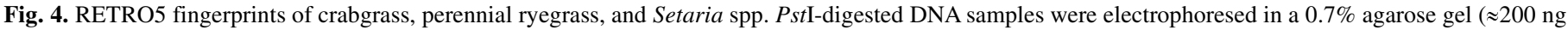

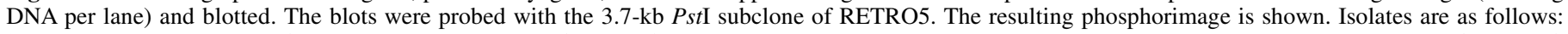

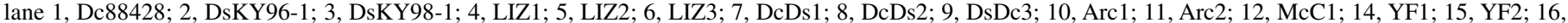

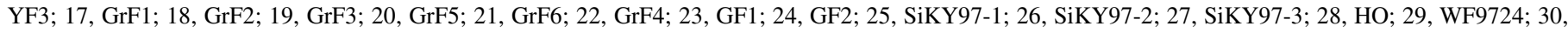

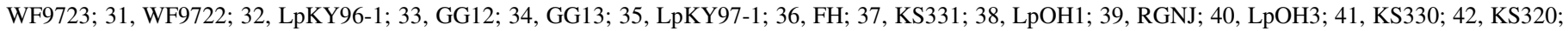
43, GG11; 44, GG9; 45, CHRF; 46, FAMS; 47, TFRGA; 48, TF97-1; and 49, CHW. Hosts of origin are noted above respective lanes. 
two groups of isolates had several fingerprint bands in common, the wheat blast isolates consistently had fewer copies of the Pot2 and MGR583 transposons than the vast majority of those causing gray leaf spot. In addition, all the isolates from prg possessed the MAT1-2 mating-type allele, which is quite rare (allele frequency = $\approx 6 \%$ ) in the wheat blast population (33). Finally, the latter isolates lack sequences hybridizing to MAGGY and MGR586, elements that are widely present in the gray leaf spot population. These

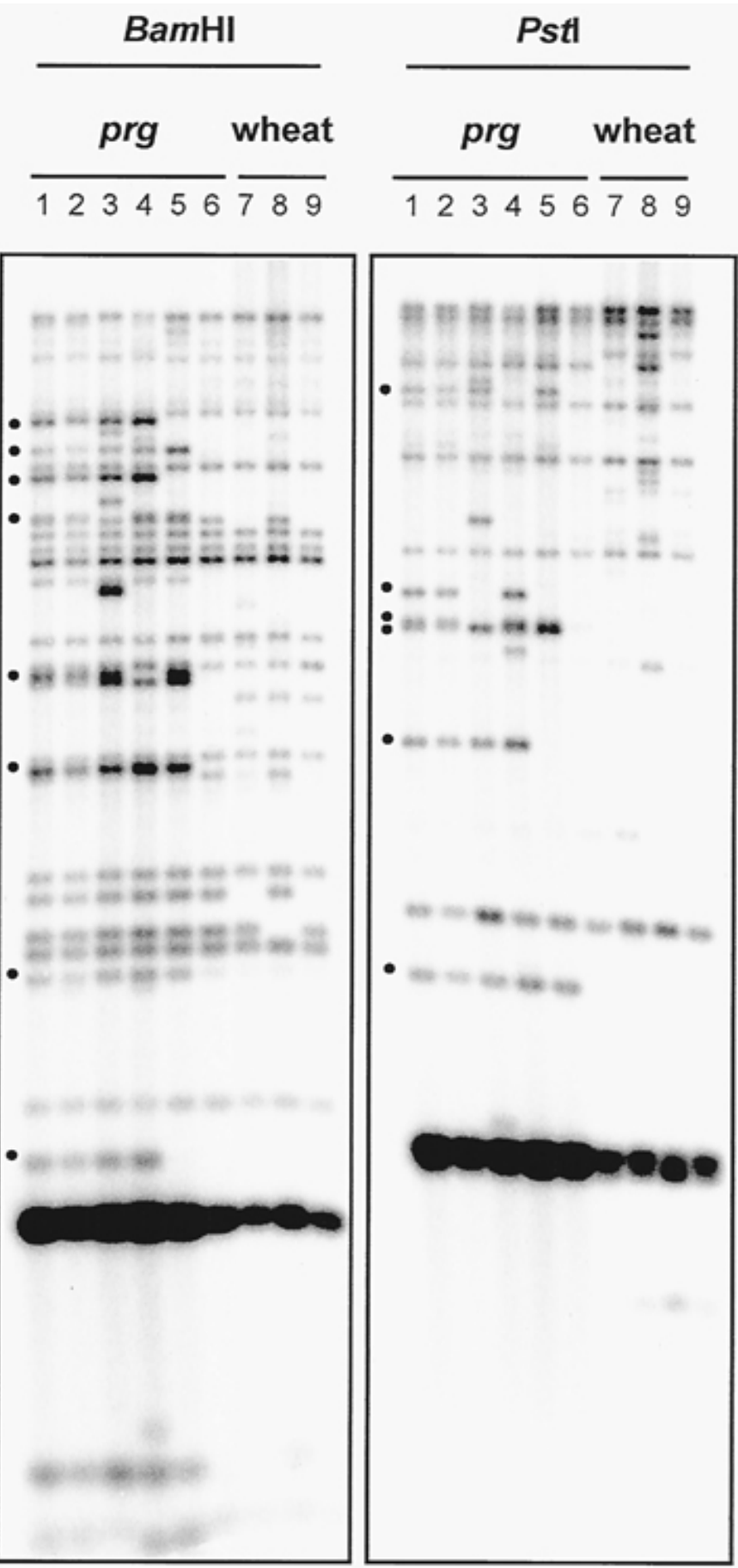

Fig. 5. Pot 2 fingerprints. DNA samples from six representative perennial ryegrass (prg) isolates and three wheat isolates were digested with BamHI or PstI, electrophoresed in $0.7 \%$ agarose gels (approximately $200 \mathrm{ng}$ per lane), and blotted to membranes. The blots were probed with the $0.9-\mathrm{kb}$ internal fragment of Pot2. Isolates are as follows: lane 1, HO; 2, Lp96-1; 3, FH; 4, GG11; 5, CHRF; 6, CHW; 7,Br32; 8, Br80; and 9, Br81. Hosts of origin are noted above the respective lanes. Pot2-containing fragments that were present in most of the isolates from prg but missing from the wheat pathogens are highlighted with black dots. results suggest that, rather than being a direct cause of the disease, the wheat blast population is a progenitor to the forms causing gray leaf spot. Isolate $\mathrm{CHW}$ is clearly an exception in that its molecular profile is essentially the same isolates that cause wheat blast. However, this profile was found in only one gray leaf spot isolate among over 50 analyzed and, therefore, cross infection of prg by fungal strains specialized to wheat appears to be a minor factor in past epidemics. Equally important, Pot2 and MGR583 fingerprints typical of prg pathogens were not found in any of the Brazilian wheat blast isolates (Fig. 5) (M. Farman, unpublished data). From this, I conclude that past wheat blast epidemics were not caused by $P$. grisea isolates from prg.

The RFLP analysis showed that the prg/wheat pathogens are quite different from the finger millet isolates, which is surprising because they share identical ITS sequences with the latter isolates. This incongruence between the RFLP phenogram (Fig. 6) and the ITS sequence data is consistent with the hypothesis that genetic recombination has occurred sometime during the evolution of these $P$. grisea populations, resulting in the exchange of a portion of chromosome 2. Additional evidence for the occurrence of recombination is that the prg pathogens' haplotype for chromosome 1 marker $18 \mathrm{O} 3$ is identical to some of the isolates from Eleusine and Eragrostis spp. However, it is different from the 1803 haplotypes of the wheat pathogens that occupy the prg clade (data not shown). This indicates an exchange of markers on chromosome 1 . Finally, isolates from the prg pathogen lineage have acquired the MGR586 and MAGGY elements, neither of which is present in the progenitor wheat blast population. In addition, MAGGY, Pot2, and MGR583 have all been amplified subsequent to the divergence of the gray leaf spot lineage. Only rice-pathogenic isolates of $P$. grisea are known to have high copy numbers of both MGR586 and MAGGY. This suggests that a progenitor to the prg pathogens may have received a small genetic contribution from a rice pathogen, perhaps through transmission of a supernumerary (b-) chromosome (1). This possibility will be the subject of future investigation.

The artificial inoculation studies performed by Urashima et al. showed that prg and Setaria spp. are both susceptible to infection by $P$. grisea isolates from wheat (33). However, the results of the present study revealed that cross infection of prg by wheat blast isolates was minimal. Similarly, there was no evidence for infection of Setaria spp. by any strains other than those with Setariatype fingerprints. Molecular analyses of $P$. grisea field isolates (35) have failed to confirm predictions of cross infectivity that were based on inoculation assays $(18,33)$. Indeed, to my knowledge, there are no examples of a single $P$. grisea population causing disease epidemics on more than one host genus. In the case of gray leaf spot, past epidemics were clearly not due to infection of prg by $P$. grisea strains specialized to other hosts, even though the grass may have been severely stressed by high temperatures. However, it is important to note that the present findings do not rule out the possibility that reciprocal cross infections may become significant epidemiological factors in the future. I would not expect $P$. grisea isolates from prg to threaten U.S. wheat production because the latter crop is grown in regions, or at times, where gray leaf spot is not active. However, based on the genetic similarity between prg and wheat pathogens revealed in this study, with the inoculation data of Urashima et al. (33), it seems that cross infection between U.S. prg and Brazilian wheat may be quite likely. In this regard, it may be simply that geographic separation between the two pathogen populations has prevented this from occurring thus far. Knowledge of the genetic constitution of the two pathogen populations, along with the use of molecular markers to monitor disease outbreaks, will enable cross infection to be detected, allowing for implementation of strategies to control diseases in both hosts.

The question remains as to why gray leaf spot emerged so swiftly as a major disease of prg. Clearly temperature was, and 


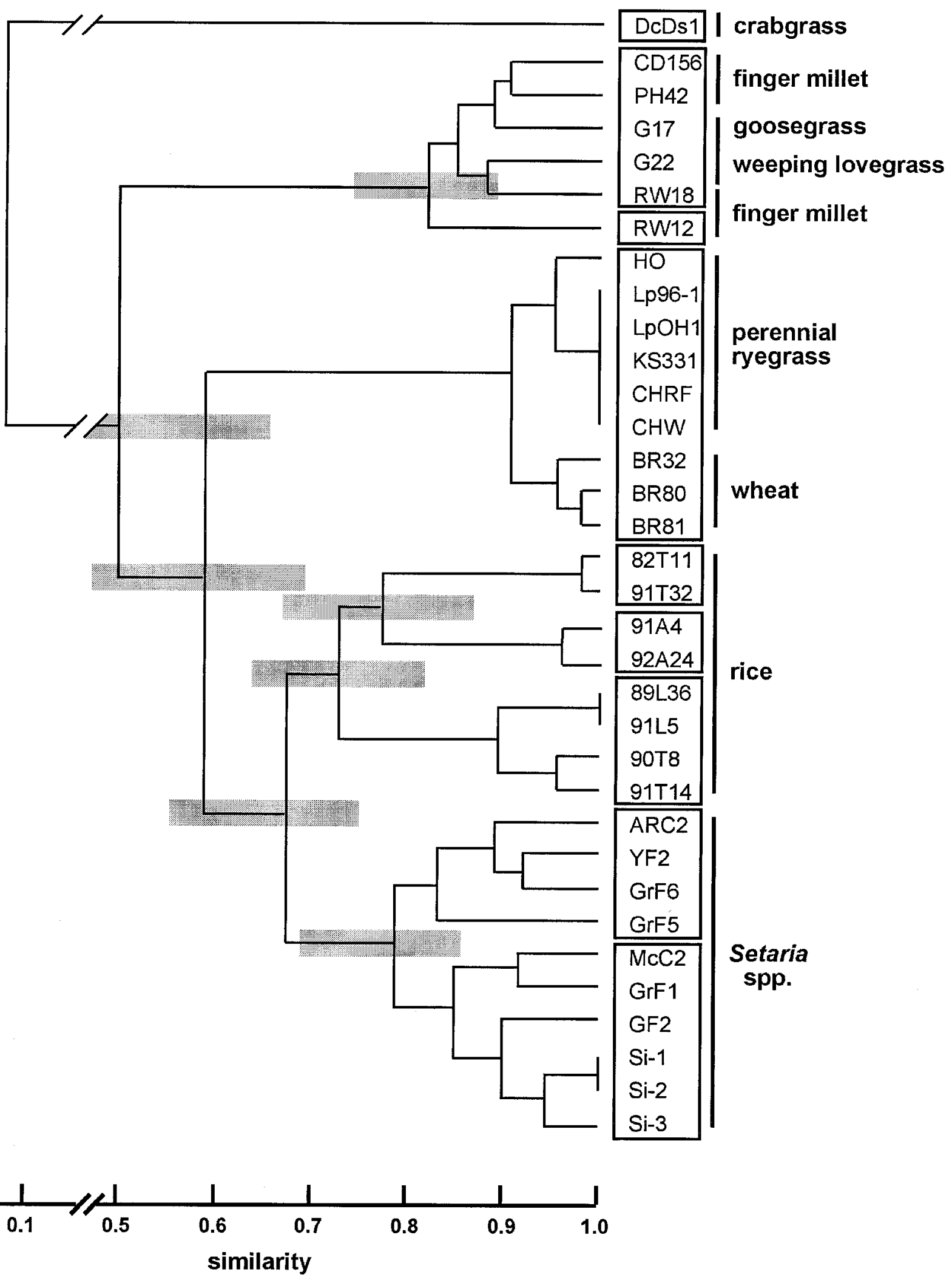

Fig. 6. Unweighted pair-group method with arithmetic average phenogram of single-copy restriction fragment length polymorphism (RFLP) variation between fungal isolates used in this study. Similarity is shown at the bottom. Clusters were classified as discreet if their constituent isolates showed less than $90 \%$ RFLP similarity to isolates in other clusters. This was determined by using the 5 to $95 \%$ confidence interval of a bootstrap analysis with 1,000 replications. The gray boxes show the $95 \%$ confidence intervals for the values at nodes separating each cluster. Isolates that co-clustered based on the above criterion are branched together. Adjacent nodes with nonoverlapping intervals indicate that the branching order has statistical support. The names for LpKY96-1, SiKY97-1, SiKY972, and SiKY97-3 are abbreviated. 
continues to be, a major factor in disease development because gray leaf spot has not affected prg in the upper Midwestern states. However, prior to 1995 , the major factor limiting epidemic development of the disease was probably the size of the pathogen population. Use of prg as a turf grass in the United States is a recent development, having started in the mid-1980s, expanding rapidly in the subsequent decade. Based on the observations of Dernoeden (3), it appears that the pathogen has been present as long as its host but the population was probably too small to allow an epidemic to develop over the course of a season. The isolated outbreaks that were reported (and others that were probably not noticed) undoubtedly resulted in an expansion of the population's size and range, leading to widespread and devastating disease once the appropriate environmental conditions were met.

\section{ACKNOWLEDGMENTS}

This work was supported by Hatch Grant KY012009 from the Kentucky Agricultural Experiment Station. This is K.A.E.S. manuscript 01-12-155. I thank P. Vincelli for getting me interested in gray leaf spot; M. Levy for providing me with the SAS programs; M. Levy and P. Anderson for assistance with the UPGMA analysis; the assistance of the scientists listed in Table 2, in providing me with $P$. grisea cultures; Y. Tosa, who supplied DNA samples of the wheat pathogen isolates; the technical support of M. Olmstead and D. Thornbury; and L. Vaillancourt, P. Vincelli, and T. Pirone for critical reading of the manuscript.

\section{LITERATURE CITED}

1. Covert, S. F. 1998. Supernumerary chromosomes in filamentous fungi. Curr. Genet. 33:311-319.

2. Darbyshire, S. J. 1993. Realignment of Festuca subgenus Schedonorus with genus Lolium (Poaceae). Novon 3:239-243.

3. Dernoeden, P. H. 1996. Perennial ryegrass and gray leaf spot. Golf Course Management 49-52.

4. Farman, M. L. Meiotic deletion of the BUF1 locus of the fungus Magnaporthe grisea is controlled by interaction with the homologous chromosome. Genetics (In press.)

5. Farman, M. L., Eto, Y., Nakao, T., Tosa, Y., Nakayashiki, H., Mayama, S., and Leong, S. A. 2002. Analysis of the structure of the AVR1-CO39 avirulence locus in virulent rice-infecting isolates of Magnaporthe grisea. Mol. Plant-Microbe Interact. 15:6-16.

6. Farman, M. L., and Leong, S. A. 1998. Chromosome walking to the AVR1-CO39 avirulence gene of Magnaporthe grisea: Discrepancy between the physical and genetic maps. Genetics 150:1049-1058.

7. Farman, M. L., Taura, S., and Leong, S. A. 1996. The Magnaporthe grisea DNA fingerprinting probe MGR586 contains the $3^{\prime}$ end of an inverted repeat transposon. Mol. Gen. Genet. 251:675-681.

8. Farman, M. L., Tosa, Y., Nitta, N., and Leong, S. A. 1996. MAGGY, a retrotransposon found in the genome of the rice blast fungus, Magnaporthe grisea. Mol. Gen. Genet. 251:665-674.

9. Free, S. J., Rice, P. W., and Metzenberg, R. L. 1979. Arrangement of the genes coding for ribosomal ribonucleic acids in Neurospora crassa. J. Bacteriol. 137:1219-1226.

10. Grandbastien, M. A., Spielmann, A., and Caboche, M. 1989. Tnt1, a mobile retroviral-like transposable element of tobacco isolated by plant cell genetics. Nature 337:376-380.

11. Hamer, J. E., Farrall, L., Orbach, M. J., Valent, B., and Chumley, F. G. 1989. Host species-specific conservation of a family of repeated DNA sequences in the genome of a fungal plant pathogen. Proc. Natl. Acad. Sci. USA 86:9981-9985

12. Harmon, P., Rane, K., Ruhl, G., and Latin, R. 2000. First report of gray leaf spot on perennial ryegrass in Indiana. Plant Dis. 84:492.

13. Henikoff, S., and Comai, L. 1998. A DNA methyltransferase homolog with a chromodomain exists in multiple polymorphic forms in Arabidopsis. Genetics 149:307-318.

14. Kachroo, P., Ahuja, M., Leong, S. A., and Chattoo, B. B. 1997. Organisation and molecular analysis of repeated DNA sequences in the rice blast fungus Magnaporthe grisea. Curr. Genet. 31:361-369.

15. Kachroo, P. K., Chattoo, B. B., and Leong, S. A. 1994. Pot2, an inverted repeat transposon from Magnaporthe grisea. Mol. Gen. Genet. 245:339348.

16. Kang, S., Chumley, F. G., and Valent, B. 1994. Isolation of the matingtype genes of the phytopathogenic fungus Magnaporthe grisea using genomic subtraction. Genetics 138:289-296.

17. Kim, C. K., and Mogi, S. 1986. Effect of temperature treatments on the penetration and disease development in the leaf epidermis by the rice blast fungus, Pyricularia oryzae CAVARA 1. Effect of pre- and postdisposing temperature on the disease development of rice blast. Ann. Phytopathol. Soc. Jpn. 52:184-192.

18. Kumar, A., and Singh, R. A. 1995. Host range of some isolates of Magnaporthe grisea and their grouping into forma specialis. Indian Phytopathol. 48:210-212.

19. Landschoot, P. J., and Hoyland, B. F. 1992. Gray leaf spot of perennial ryegrass in Pennsylvania. Plant Dis. 76:1280-1282.

20. Leong, S. A., Farman, M. L., Smith, J., Budde, A., Tosa, Y., and Nitta, N. 1994. Molecular-genetic approach to the study of cultivar specificity in the rice blast fungus. Pages 87-110 in: Rice Blast Disease. R. S. Zeigler, S. A. Leong, and P. S. Teng, eds. CAB International, Wallingford, UK.

21. Levy, M., Correa-Victoria, F. J., Zeigler, R. S., Xu, S., and Hamer, J. E. 1993. Genetic diversity of the rice blast fungus in a disease nursery in Colombia. Phytopathology 83:1427-1433.

22. Levy, M., Romao, J., Marchetti, M. A., and Hamer, J. E. 1991. DNA fingerprinting with a dispersed repeated sequence resolves pathotype diversity in the rice blast fungus. Plant Cell 3:95-102.

23. Miller, J. C. 1991. RESTSITE: A phylogenetic program that sorts raw restriction data. J. Hered. 82:262-263.

24. Nei, M., and Li, W. H. 1979. Mathematical model for studying genetic variation in terms of restriction endonucleases. Proc. Natl. Acad. Sci. USA 76:5269-5273.

25. Nitta, N., Farman, M. L., and Leong, S. A. 1997. Genome organization of Magnaporthe grisea: Integration of genetic maps, clustering of transposable elements and identification of genome duplications and rearrangements. Theor. Appl. Genet. 95:20-32.

26. Noma, K., Nakajima, R., Ohtsubo, H., and Ohtsubo, E. 1997. RIRE1, a retrotransposon from wild rice, Oryza australiensis. Genes Genet. Syst. 72:131-140.

27. Raeder, U., and Broda, P. 1985. Rapid preparation of DNA from filamentous fungi. Lett. Appl. Microbiol. 1:17-20.

28. Schumann, G., and Jackson, N. 1999. First report of gray leaf spot (Pyricularia grisea) on perennial ryegrass (Lolium perenne) in New England. Plant Dis. 83:1073.

29. Thornbury, D. W., and Farman, M. L. 2000. Re-use of nylon membranes for radioactive hybridizations. Biotechniques 29:1250-1254.

30. Tosa, Y., Nakayashiki, H., Hyodo, H., Mayama, S., Kato, H., and Leong, S. A. 1995. Distribution of retrotransposon MAGGY in Pyricularia species. Ann. Phytopathol. Soc. Jpn. 61:549-554.

31. Trevathan, L. E. 1982. Response of ryegrass plant introductions to artificial inoculation with Pyricularia grisea under greenhouse conditions. Plant Dis. 66:696-697.

32. Uddin, W., Soika, M. D., Moorman, F. E., and Viji, G. 1999. A serious outbreak of blast disease (gray leaf spot) of perennial ryegrass fairways in Pennsylvania. Plant Dis. 83:783.

33. Urashima, A. S., Igarashi, S., and Kato, H. 1993. Host Range, mating type and fertility of Pyricularia grisea from wheat in Brazil. Plant Dis. 77:1211-1216.

34. Valent, B., Farrall, L., and Chumley, F. G. 1986. Genetic studies of fertility and pathogenicity in Magnaporthe grisea (Pyricularia oryzae). Iowa State J. Res. 60:569-594.

35. Viji, G., Gnanamanickam, S. S., and Levy, M. 2000. DNA polymorphisms of isolates of Magnaporthe grisea from India that are pathogenic to finger millet and rice. Mycol. Res. 104:161-167.

36. Viji, G., Wu, B., Kang, S., Uddin, W., and Huff, D. R. 2001. Pyricularia grisea isolates causing gray leaf spot of perennial ryegrass turf: Population structure and host specificity. Plant Dis. 85:817-826.

37. Viji, G., Wu, B., Uddin, W., and Kang, S. 1999. Characterization of Pyricularia grisea isolates from perennial ryegrass from various geographic regions in the United States. (Abstr.) Phytopathology 89(suppl.):S80.

38. Xia, J. Q., Correll, J. C., Lee, F. N., Marchetti, M. A., and Rhoads, D. D. 1993. DNA fingerprinting to examine microgeographic variation in the Magnaporthe grisea (Pyricularia grisea) population in two rice fields in Arkansas. Phytopathology 83:1029-1035. 


\section{Erratum}

Vol. 92, No. 3, 2002

In the manuscript entitled "Pyricularia grisea Isolates Causing Gray Leaf Spot on Perennial Ryegrass (Lolium perenne) in the United States: Relationship to P. grisea Isolates from Other Host Plants" by M. L. Farman (Phytopathology 92:245-254), there are three text changes. On page 249 , lines three to five in paragraph three should read ".. the ITS region of the rDNA repeat in gray leaf spot isolates was identical to sequences found in P. grisea isolates from wheat (T. aestivum) and Triticale (X Triticosecale), and showed similarity to isolates from Eleusine spp." On page 251, the first sentence in paragraph six should read "... ITS sequence of rDNA in the prg pathogens was identical to those found in P. grisea isolates from wheat and Triticale spp. (36,37)." On page 252, the first sentence in paragraph two should read "The RFLP analysis showed that the prg/wheat pathogens are quite different from the finger millet isolates, which is surprising because they share very similar ITS sequences with the latter isolates." 